\title{
DOSSIÊ
}

Sociologias, Porto Alegre, ano 17, no 38, jan/abr 2015, p. 14-17

Apresentação do dossiê

\section{Tendências e Desafios Contemporâneos da Sociologia Política}

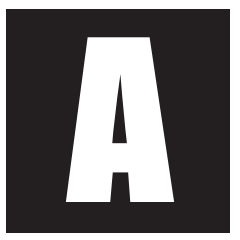

Sociologia no Brasil constitui-se inicialmente como uma Sociologia Política (Reis, 1996; Sallum Jr., 2002). Somente depois da metade dos anos 1960, Sociologia e Ciência Política passaram a ser ensinadas como campos de conhecimento distintos. A não diferenciação verificada anteriormente refletia, ao mesmo tempo, um baixo grau de especialização acadêmica e uma visão altamente politizada da sociedade (Reis, 1996). Engajados no projeto de construção da nação e do Estado e, principalmente depois da segunda metade dos anos 1960, preocupados com o desenvolvimento (Sallum Jr., 2002), os cientistas sociais brasileiros produziram uma Sociologia politizada. Os estudos "sobre estratificação e mobilidade social, urbanização, industrialização, migração rural-urbana ou outros fenômenos sociais usualmente acentuavam as implicações políticas dos processos societais" (Reis, 1996, p. 81).

A consolidação da Ciência Política como disciplina separada da Sociologia, no entanto, não afastou os sociólogos da preocupação em procurar compreender, ou por vezes explicar, como se configuram as re-

\footnotetext{
* Universidade Federal do Rio Grande do Sul (Brasil).
} 
Sociologias, Porto Alegre, ano 17, no 38, jan/abr 2015, p. 14-17

lações entre Estado e Sociedade; quais são e como se expressam as bases societais do poder estatal, os processos macro-políticos de mudança, as desigualdades políticas, as disputas políticas de grupos organizados pelo poder em campos setoriais de políticas públicas. Isso, para destacar apenas alguns dos temas que têm mobilizado os esforços dos sociólogos brasileiros. O presente dossiê apresenta quatro artigos que refletem sobre a sociologia política contemporânea e um artigo que exemplifica como os sociólogos podem abordar problemáticas na área.

O conjunto que trata da própria sociologia política inicia com o texto 'Sociologia política e processos macro-históricos' de Elisa Reis. No estudo, enquanto aponta a existência de uma grande diversidade de abordagens na Sociologia Política, a autora dá destaque às análises macro-históricas que observam os grandes processos de transformação. Ao adotar esta perspectiva analítica, Reis discute algumas das transformações em curso e sugere que elas colocam desafios teóricos e metodológicos relevantes, não apenas para a sociologia política, como também para 'a Sociologia' como disciplina.

O segundo artigo, 'Desafios para uma sociologia política brasileira: os elos entre movimentos e instituições', de Ilse Scherer-Warren, discute as dificuldades que a sociologia política enfrenta em face de especializações paradigmáticas, destacando o desenvolvimento paralelo ocorrido no Brasil dos estudos institucionalista-estatais versus os centrados na cultura-política, em especial, da sociedade civil. A autora também salienta as dificuldades impostas pelo legado da colonialidade às pesquisas em centros não hegemônicos e alerta para a necessidade de uma abordagem temática para a Sociologia Política, que fortaleça o diálogo entre enfoques institucionalistas e da cultura-política no Brasil contemporâneo.

O terceiro artigo, 'Sociologia Política na Alemanha desde os anos de 1990 - desenvolvimento da sub-disciplina e problemas atuais', de Katrin Möltgen e Malte Schophaus, examina o desenvolvimento da sociologia 
Sociologias, Porto Alegre, ano 17, no 38, jan/abr 2015, p. 14-17

política alemã ao longo do século. Os autores concentraram a análise no seu desenvolvimento ao longo das últimas três décadas e demonstram que, embora os tópicos de sociologia política abranjam muitas áreas da Sociologia e da Ciência Política, a sociologia política não logrou tornar-se uma disciplina no sistema universitário.

No quarto estudo, 'A quem pertence o estudo da democracia? Sociologia, ciência política e a promessa da interdisciplinaridade na Sociologia Política desde 1945', de Joshua Kjerulf Dubrow e Marta Kolczynska, os autores argumentam que a sociologia política já foi considerada uma ponte natural entre as disciplinas de Sociologia e Ciência Política. Contudo, sugerem que os vínculos entre essas duas disciplinas são cada vez mais fracos. A partir da década de 1970, a Ciência Política passou a monopolizar o estudo da democracia, e a sociologia política tornou-se um exemplo de como pode fracassar uma grande promessa de interdisciplinaridade.

O quinto artigo, 'Policy community defensora de direitos e a transformação do Conselho Nacional de Assistência Social', de minha autoria, apresenta um exemplo de pesquisa no campo da sociologia política. No caso, a análise de mudanças em uma política setorial, focalizando a ação estratégica dos atores. O argumento central é de que a ação estratégica da policy community defensora da assistência social como direito dos cidadãos, resultou não apenas na criação do Sistema Único de Assistência Social (SUAS), mas também na redefinição das funções do Conselho Nacional de Assistência Social (CNAS), ao final da década de 2000. O CNAS, uma organização intermediária neocorporativa criada pela Lei Orgânica da Assistência Social, consolidou o seu papel na intermediação de interesses entre os diversos atores societais e estatais visando viabilizar a implementação das políticas definidas no nível federal de gestão que resultaram na estruturação do SUAS. 
Sociologias, Porto Alegre, ano 17, no 38, jan/abr 2015, p. 14-17

A expectativa, ao organizar este dossiê, é colaborar para que se reflita sobre o modo como a Sociologia, particularmente no Brasil, tem abordado a dimensão do Estado e da política nos processos sociais. Desse modo, espera-se ampliar os horizontes dos pesquisadores da temática, não apenas na área de Sociologia, mas em outros campos de conhecimento da área de humanidades.

Soraya Vargas Cortês - Doutora em Social Policy and Administration pela London School of Economics and Political Science (1995). Atualmente é professora do Departamento e Programa de Pós-Graduação em Sociologia da Universidade Federal do Rio Grande do Sul, Pesquisadora do CNPQ, coordenadora adjunta do Comitê de Avaliação da Pós-Graduação da Capes, na Sub-Área de Sociologia e Presidente da Sociedade Brasileira de Sociologia.

$\measuredangle$ vargas.cortes@ufrgs.br 